Article

\title{
Anthocyanin Accumulation and Color Development of 'Benitaka' Table Grape Subjected to Exogenous Abscisic Acid Application at Different Timings of Ripening
}

\author{
Muhammad Shahab ${ }^{1}$, Sergio Ruffo Roberto ${ }^{1, *(1)}$, Saeed Ahmed ${ }^{1}$, Ronan Carlos Colombo ${ }^{1}$, \\ João Pedro Silvestre ${ }^{1}$, Renata Koyama ${ }^{1}$ and Reginaldo Teodoro de Souza ${ }^{2}$ \\ 1 Agricultural Research Center, Department of Agronomy, Londrina State University, Londrina, \\ PR 86057-970, Brazil; mshahab78@gmail.com (M.S.); saeeddikhan@gmail.com (S.A.); \\ ronancolombo@yahoo.com.br (R.C.C.); jp.silvestre@gmail.com (J.P.S.); emykoyama@hotmail.com (R.K.) \\ 2 Embrapa Grape and Wine, Tropical Station Unit., Bento Gonçalves, RS 95700-000, Brazil; \\ reginaldo.souza@embrapa.br \\ * Correspondence: sroberto@uel.br; Tel.: +55-43-3371-4774
}

Received: 14 January 2019; Accepted: 9 February 2019; Published: 28 March 2019

\begin{abstract}
In colored table grapes, the anthocyanin contents are inhibited by the high temperature during ripening and berries suffer a lack of skin color, thus affecting their market value. In order to overcome this issue, a research study was planned to evaluate the influence of (S)-cis-abscisic acid (S-ABA) on rates of anthocyanin accumulation in table grapes when applied at different timings of ripening, and to quantify the gradual increase of berry color. The study was conducted in a commercial vineyard of 'Benitaka' table grapes (Vitis vinifera L.), grown under double annual cropping system in a subtropical area. The trials were carried out during two consecutive seasons (i.e., summer season of 2015 and off-season of 2016). The treatments used for the experiments contained $400 \mathrm{mg} \mathrm{L}^{-1} \mathrm{~S}$-ABA applied at different timings of veraison (the onset of ripening), as follows: control (with no application); at pre-veraison (PRV); at veraison (V); and at post-veraison (POV). For all $S$-ABA treatments, a second application was performed 10 days after the first application. Berries were analyzed for weekly and daily anthocyanin accumulations, weekly and daily color index development (CIRG), total soluble solids (TSS) content, titratable acidity (TA), and maturation index (TSS/TA). Grapes subjected to exogenous application of S-ABA at any time of veraison, especially at PRV or at $\mathrm{V}$, significantly increased the anthocyanin accumulation as well as berry color index development. Other chemical properties of grapes (i.e., TSS, TA, and TSS/TA evolution) were not affected by the use of $S$-ABA and followed a predictable pattern in relation to days of berries ripening.
\end{abstract}

Keywords: Vitis vinifera L.; production system; S-ABA; rate of anthocyanin accumulation; CIRG; bioactive compounds

\section{Introduction}

Table grapes are a rich source of phenolic compounds with antioxidant and anti-inflammatory properties, which are helpful in preventing several human diseases [1-3]. These secondary metabolites are present in different parts of berries, where skin is enriched with anthocyanins, pigments responsible for the red, pink, or black color [4,5], and in some cultivars these pigments can also be found in the flesh [6,7].

However, when colored table grapes are grown in subtropical areas, high temperatures during ripening may inhibit anthocyanin accumulation and prevent color development, thus negatively 
affecting the market value of the table grapes, since the skin color is a very important economic feature [7-9]. In addition, in some subtropical regions, due to the mild winter and the use of bud burst stimulators, a double annual cropping of grapes can be achieved. Therefore, besides the summer season crop, an off-season crop is obtained when there is no or less supply of fresh grapes in the market [10].

'Benitaka' (Vitis vinifera L.) is one of the most important colored table grapes developed from the bud sport of 'Italia' grape [11]. Interest in growing this cultivar has been increasing due to its dark pink color and uniform, large, and crunchy berries, and in some regions, such as the Brazilian subtropics, this grape represents more than $50 \%$ of the area cultivated by table grapes. However, lack of skin color is an issue while growing this cultivar in this kind of subtropical warm climates $[9,10]$.

In grapes, the anthocyanin starts accumulating at the time when abscisic acid (ABA) also starts to increase in berries, and is reportedly responsible for the anthocyanin biosynthesis [6,7]. In recent years, it has been demonstrated that the application of the enantiomer (S)-cis-abscisic acid (S-ABA) can increase the anthocyanin contents of grapes and improve their color $[6,7,9,12-16]$.

Exogenous application of $S$-ABA is effective around the time of veraison (onset of ripening), a time when physiological changes start to appear in grapes, such as the increase of soluble solids, berry softening, and coloring [15,17]. However, in most of the cases, application of $S$-ABA at the time of veraison is a difficult task, especially because the onset of these changes does not occur simultaneously and may widely vary among cultivars [18]. Additionally, large growing areas and unfavorable climatic conditions, such as prolonged rainfall periods, make it difficult to apply this plant growth regulator at veraison in a short period of time over the whole area, since it is a time-consuming operation and only the bunches are subjected to the application.

Considering these aspects, an evaluation of the effect of S-ABA application over a longer period of time (i.e., from pre- to post-veraison) on color development has not been explored yet, especially regarding the weekly and daily rates of anthocyanin development, which could provide information leading to a better understanding of the responses of berries towards such treatments in different circumstances. In order to overcome this issue, a research study was planned to evaluate the influence of S-ABA on anthocyanin accumulation when applied at different timings of veraison, and to quantify the gradual increase of berry color in 'Benitaka' table grapes grown under double annual cropping in a subtropical area.

\section{Materials and Methods}

\subsection{Experimental Area and Pre-Conditions}

The study was conducted in an 11-year-old commercial vineyard of 'Benitaka' table grapes (Vitis vinifera L.), grafted on 'IAC 766 Campinas' rootstock located at Marialva city, in the state of Parana, Brazil ( $23^{\circ} 29^{\prime} 52.8^{\prime \prime} \mathrm{S}, 51^{\circ} 47^{\prime} 58^{\prime \prime} \mathrm{W}$, elevation $\left.570 \mathrm{~m}\right)$, under double annual cropping system. The climate of this area is classified as Cfa by Köppen (i.e., subtropical humid) with winter mean temperature below $18{ }^{\circ} \mathrm{C}$, summer mean temperature above $22^{\circ} \mathrm{C}$ and $1596 \mathrm{~mm}$ of rainfall, which occurs mostly during summer [19]. The trials were carried out during two consecutive seasons (i.e., summer season of 2015 and off-season of 2016). The total precipitation and average temperature during the grape ripening period of the 2015 summer season and 2016 off-season were $462 \mathrm{~mm}$ and $23.0^{\circ} \mathrm{C}$ and $290 \mathrm{~mm}$ and $17.5^{\circ} \mathrm{C}$, respectively. The vines were spaced at a distance of $3.0 \times 6.0 \mathrm{~m}$ and cane-pruned with eight buds per cane. For uniform bud burst, $2.5 \%$ of hydrogen cyanamide was applied on the two terminal buds. Other practices like fertilizer application, weed control, pest and disease management were carried out according to the local practices used [9].

\subsection{Treatments and Statistical Design}

The isomer (S)-cis-abscisic acid (S-ABA) was provided by Valent BioSciences ${ }^{\circledR}$ Co. (Illinois, Libertyville, IL, USA), containing $100 \mathrm{~g} \mathrm{~L}^{-1}$ of active ingredient. The experiments were conducted in a 
randomized block design, where the treatments were replicated five times, and each plot consisted of one single vine. Ten representative bunches per each plot were marked for further analysis.

The treatments contained S-ABA $400 \mathrm{mg} \mathrm{L}^{-1}[9,15]$ applied at different timings of veraison, as follows: control (with no application); at pre-veraison (PRV); at veraison (V); and at post-veraison (POV). For all S-ABA treatments, a second application was performed 10 days after the first application in order to potentialize anthocyanin accumulation, according to previous works with this and other grape cultivars $[9,15]$. Application timings were identified considering the total soluble solids (TSS) of berries. The first treatment (at PRV) was applied when the berry TSS contents suddenly jumped from 4.0 to 5.7 Brix. Similarly, for the second treatment (at V), TSS was 7.3 Brix and at least $50 \%$ of the berries showed change in color, performed 7 days after PRV. The last treatment (at POV) was also applied 7 days after $\mathrm{V}$, where the TSS was 9.5 Brix.

For S-ABA application, only the bunches of the 'Benitaka' table grapes were sprayed using a knapsack sprayer at a pressure of 568.93 psi (39.22 bar) with hollow cone nozzle tips, model JA-1 (1 mm of diameter) (Jacto Group, Pompeia, Brazil), at a volume of $800 \mathrm{~L} \mathrm{ha}^{-1}$ in a complete and uniform way. In addition, $0.3 \mathrm{~mL} \mathrm{~L}^{-1}$ of BreakThru $\circledast($ Evonik Industries, Essen, Germany), a non-ionic surfactant, was added to all treatments for uniformity of the treatment.

\subsection{Sampling and Analyses}

During both evaluated seasons, anthocyanin contents, color index development, TSS, titratable acidity (TA), and maturation index (TSS/TA) were evaluated on weekly basis starting right from the application of first treatment (at PRV). For this purpose, 30 berries were randomly selected from each plot (i.e., three from each marked bunch with one from the top, one from the middle, and one from the bottom of each bunch). These samples were then split into three subsamples $(n=10)$ for further evaluation. For both seasons, bunches were harvested when the TSS of the berries stabilized at around 14.0 Brix.

\subsection{Anthocyanin Evaluations}

To determine the anthocyanin content in berries from the first treatment application (at PRV; i.e., 7 days before veraison), samples of $3 \mathrm{~g}$ of berry skin were used from each plot, which were gently separated from the flesh using a sterile blade and washed with distilled and de-ionized water. The skins were than dried with a sterilized tissue, and added to $30 \mathrm{~mL}$ of acidified methanol $(\mathrm{HCl}$ $1 \%+$ methanol $99 \%$ ) and left in the dark for $48 \mathrm{hrs}$. Spectrophotometer Genesys ${ }^{\mathrm{TM}}$ 10S UV-VIS ${ }^{\circledR}$ (Thermo Scientific, Waltham, MA, USA) at $520 \mathrm{~nm}$ was used for evaluating the samples, whereas results were expressed in milligrams of total anthocyanins as malvidin-3-glucoside per gram of berry skin $\left(\mathrm{mg} \mathrm{g}^{-1}\right)$ [8]. For evaluating the weekly rate of anthocyanin accumulation (from one week after the treatments application), readings from earlier samples were subtracted from the later ones and divided by the total number of days (i.e., 7 days), and the results were expressed as milligrams of malvidin-3-glucoside per gram of berry skin per day ( $\mathrm{mg} \mathrm{g}^{-1}$ of skin).

\subsection{Skin Color Evaluations}

A colorimeter CR-10 (Minolta ${ }^{\circledR}$, Tokyo, Japan) was used for skin color evaluation. For each plot, 10 berries were analyzed for color development by recording their $L^{*}$ (lightness), $C^{*}$ (chroma), and $h^{\circ}$ (hue angle). The values of light may range from 0 (black) to 100 (white). Chroma is calculated from the $a^{*}$ and $b^{*}$ of the CIELab scale system. Chroma signifies color purity or color intensity from achromatic (grey) towards chromatic color that starts from zero without any possible end point, but the intensity increases with magnitude. Hue angle refers to the color wheel (i.e., green, yellow, and red in regard to the values of 180,90 , and 0 , respectively) $[8,12,13,16]$. For color index of red grapes (CIRG) from the first treatment application (at PRV), the formula CIRG $=\left(180-h^{\circ}\right) /\left(L^{*}+C^{*}\right)$ was used [20]. The weekly rate of color index of red grape (CIRG), from one week after the application of the treatments, was 
calculated by subtracting the final CIRG values from the initial readings, and then dividing them by the total number of days (i.e., 7 days).

\subsection{Total Soluble Solids (TSS), Titratable Acidity (TA), and Maturation Index (TSS/TA)}

A digital refractometer DR301-95 (Krüss Optronic, Hamburg, Germany) was used for the TSS evaluation. For this purpose, juice was extracted from 10 berries of each plot, and the results were expressed as Brix. For titratable acidity (TA) determination, a semi-automatic titrator was used, where juice extracted from the berries was titrated with $0.1 \mathrm{~N} \mathrm{NaOH}$. The results are presented as percentage of tartaric acid [21]. The maturation index was calculated from the ratio of TSS and TA.

\subsection{Statistical Analysis}

The collected data was analyzed using analysis of variance (ANOVA) and Tukey's HSD (Honest significant difference) test was used to calculate mean significant differences at $5 \%$ probability level [22] for all the variables, including rates of anthocyanin and CIRG development. Furthermore, regression analyses were carried out for TSS, TA, and TSS/TA. These procedures were carried out using statistical software SISVAR ${ }^{\circledR}$ version 5.8 build 80 (Lavras Federal University, Lavras, Brazil) and MS Excel (Microsoft, Washington, WA, USA).

\section{Results}

\subsection{Total and Weekly Rate of Anthocyanin Accumulation}

Total anthocyanin accumulation was significantly affected in both seasons by the use of exogenous $S$-ABA applied at different timings of veraison. After two weeks of the application at PRV, the grape berries started to show increases in the anthocyanin concentration of the skin (Figure 1). During both seasons, all treatments, regardless of their application timing (i.e., at PRV, at V, and at POV), presented a significant increase throughout the berry ripening until harvest. This increase was superior among S-ABA-treated berries in comparison with control treatments from the start of veraison until harvest. It was observed that during both seasons, although at PRV and at V presented higher means as compared with at POV during the process of the berries ripening, in both cases the final means of these treatments were statistically similar to each other and significantly higher than the control treatment.

Moreover, regardless of the different timings of S-ABA application, it was clear the importance of the second application (i.e., 10 days after first one) to keep the accumulation of anthocyanin over time, and this behavior was observed during both growing seasons.

Although the final means of total anthocyanin were similar during both seasons, the development pattern of anthocyanin accumulation was slightly different. During the 2015 summer season, the anthocyanin accumulation was fast after the application of S-ABA, but at the end of the cycle, the increase seemed to stabilize. On the other hand, during 2016 off-season, this behavior varied, where the anthocyanin buildup was initially slow but acquired momentum, and even at harvest, berries showed a tendency towards producing more anthocyanin content, unlike the summer season of 2015, where anthocyanin accumulation stabilized at the time of harvest.

This phenomenon can be more clearly observed from the weekly rate of anthocyanin accumulation (Figure 1). It can be observed that during the summer season of 2015, the weekly rate of anthocyanin accumulation during early ripening stages (at 14 and 21 days after veraison - DAV) was faster as compared to later stages ( 28 and $35 \mathrm{DAV}$ ), where this development stabilized. On the other hand, during the off-season of 2016, the rate of weekly anthocyanin accumulation was not significantly high during the early stages (14 DAV) but gradually increased and was still increasing at harvest. The rate of weekly anthocyanin accumulation during the off-season of 2016 was more efficient compared to the summer season of 2015, whereas during both seasons berries treated with S-ABA at PRV showed a significantly higher accumulation rate followed by at $\mathrm{V}$ application. 

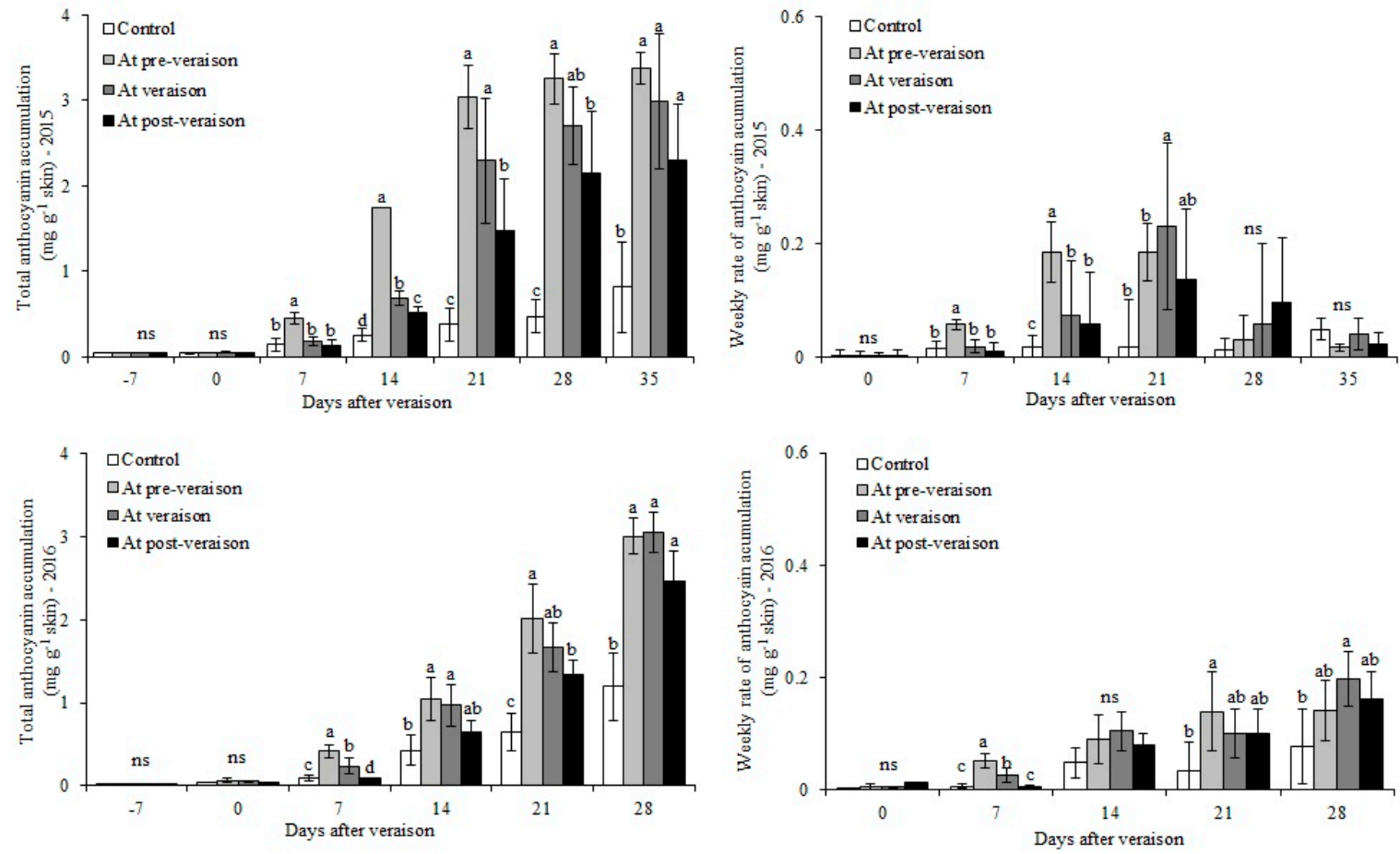

Figure 1. Total anthocyanin accumulation ( $\mathrm{mg} \mathrm{g}^{-1}$ of skin) and weekly rate of anthocyanin accumulation ( $\mathrm{mg} \mathrm{g}^{-1}$ of skin) of 'Benitaka' berries (Vitis vinifera L.) subjected to (S)-cis-abscisic acid (S-ABA $400 \mathrm{mg} \mathrm{L}^{-1}$ ) at different timings of ripening. A second application of $S$-ABA $400 \mathrm{mg} \mathrm{L}^{-1}$ was performed for all treatments 10 days after the first application, except for the control. Means within columns for the same letter followed by different letters differ significantly by Tukey's test $(p<0.05)$. ns: non-significant.

\subsection{Berries Color and Weekly Rate of Color Development}

Color development followed the same pattern observed for total anthocyanin accumulation, with a very slight variation during the 2016 off-season. Like anthocyanin color development, it started to increase more quickly in S-ABA-treated berries as compared with non-treated berries (Figure 2). During both seasons, right after the application of $S$-ABA, the treated berries showed significantly darker color in comparison to control with application at PRV and at $\mathrm{V}$ being the superior treatments in terms of color development (Figure 3). Multiple S-ABA applications showed similar effect on berries color development as anthocyanin concentration, as previously discussed.

During the 2015 summer season, early S-ABA applications (at PRV and at V) were recorded with higher anthocyanin accumulation throughout the ripening of berries, where at harvest, all treatments were significantly at par with each other, including at POV, except control. On the other hand, for the 2016 off-season, the same behavior was observed for the treatments, but with a little difference, where at harvest, S-ABA applied at POV treatment showed significantly similar results to that of at $\mathrm{V}$ application, but lower to at PRV. Overall, all the treatments during off-season were higher than control, but the treatments applied at PRV and at V were recorded with higher means. 

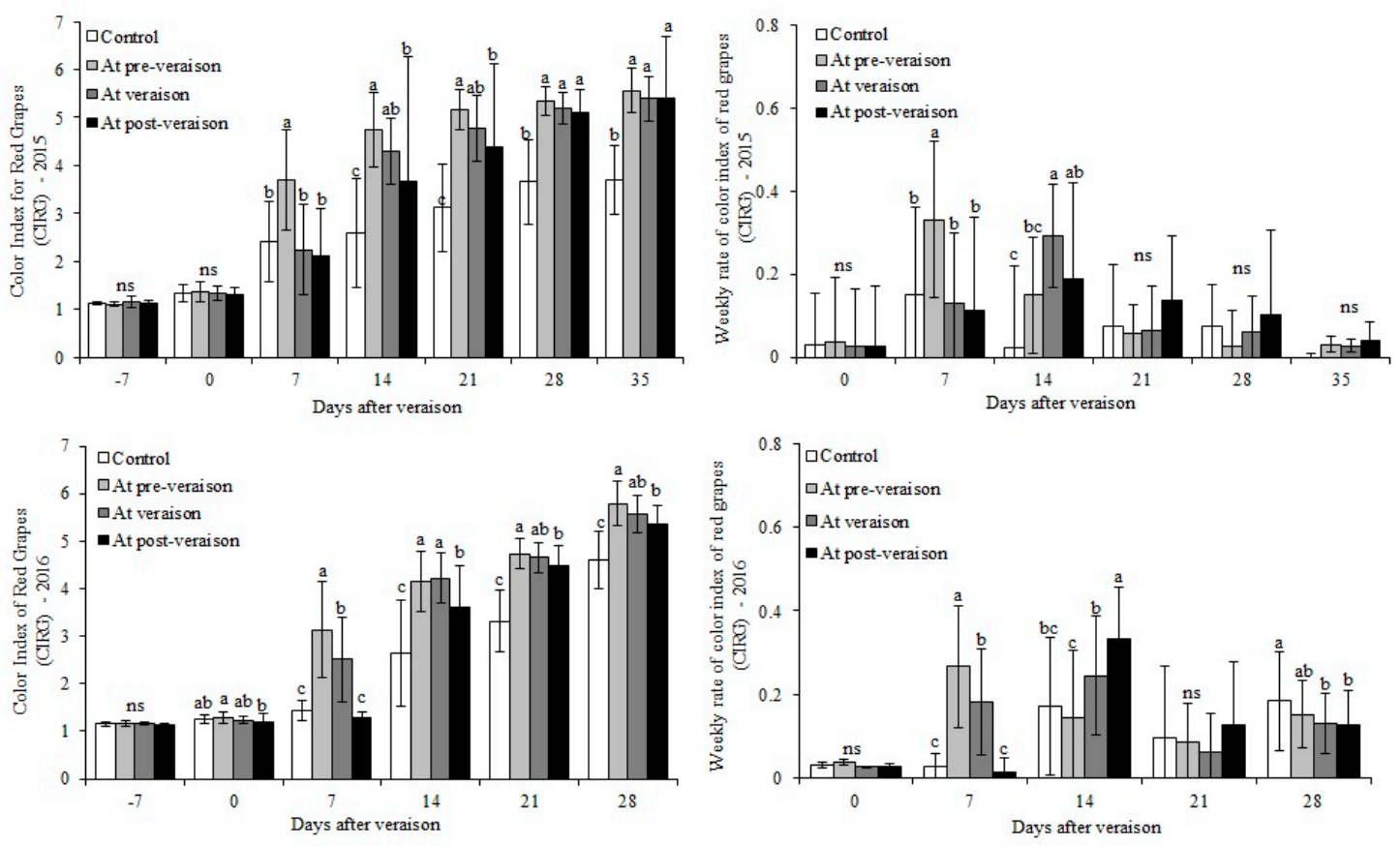

Figure 2. Color index of red grapes (CIRG) and weekly rate of color index for red grape (CIRG) of 'Benitaka' berries (Vitis vinifera L.) subjected to (S)-cis-abscisic acid (S-ABA $400 \mathrm{mg} \mathrm{L}^{-1}$ ) at different timings of ripening. A second application of $S-\mathrm{ABA} 400 \mathrm{mg} \mathrm{L}^{-1}$ was performed for all treatments 10 days after the first application, except for the control. Means within columns for the same letter followed by different letters differ significantly by Tukey's test $(p<0.05)$. ns: non-significant.

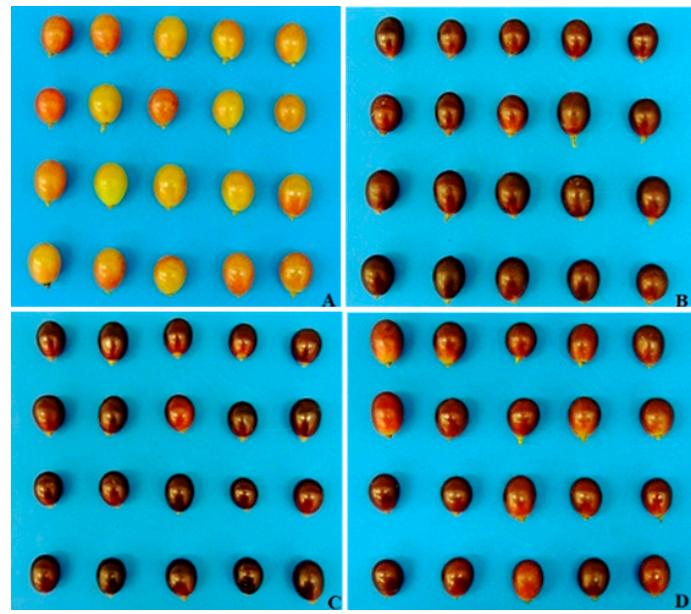

Summer season crop 2015
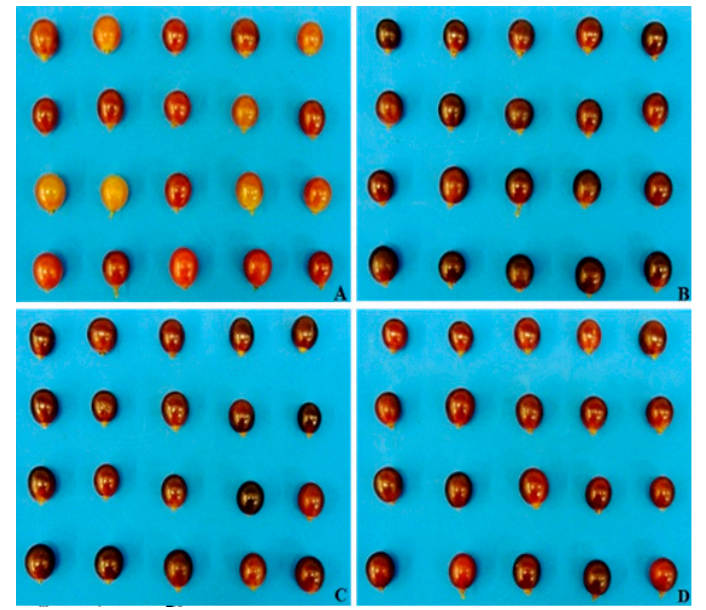

Off-season crop 2016

Figure 3. Berries of 'Benitaka' table grapes subjected to different treatments with (S)-cis-abscisic acid (S-ABA $400 \mathrm{mg} \mathrm{L}^{-1}$ ). A: control (no application); B: at pre-veraison; C: at veraison; D: at post-veraison. A second application of $S$-ABA $400 \mathrm{mg} \mathrm{L}^{-1}$ was performed for all treatments 10 days after the first application, except for the control.

\subsection{Total Soluble Solids (TSS), Titratable Acidity (TA), and Maturation Index (TSS/TA)}

Regression analysis showed that TSS contents of 'Benitaka' berries (Figure 4) developed with no effect from the S-ABA application. TSS development through the course of ripening showed a linear regression with days of berries ripening (Figure 4). All of the samples reached maximum TSS around 14 Brix during both seasons with no influence from the use of the plant growth regulator. 

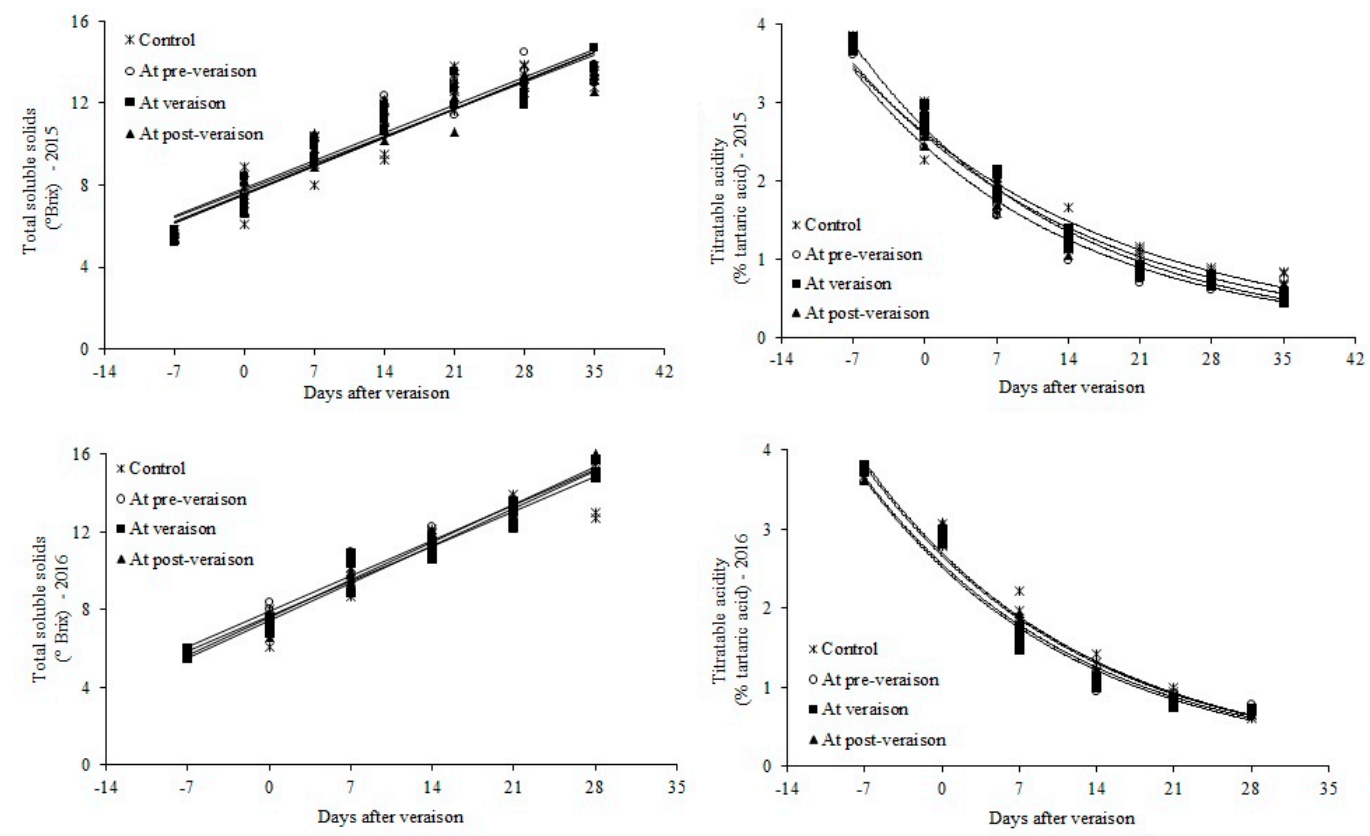

Figure 4. Evolution of total soluble solids (TSS; Brix) and titratable acidity (\% tartaric acid) of 'Benitaka' berries (Vitis vinifera L.) subjected to (S)-cis-abscisic acid (S-ABA $400 \mathrm{mg} \mathrm{L}^{-1}$ ) at different timings of veraison. A second application of $S$-ABA $400 \mathrm{mg} \mathrm{L}^{-1}$ was performed for all treatments 10 days after the first application, except for the control. Data were originated from polynomial regression.

Regression analysis of TA showed a negative polynomial behavior through the course of berries ripening in both seasons (Figure 4). Like TSS, TA was also not influenced by the use of exogenous $S$-ABA application to the berries. The same can be observed for the maturation index of 'Benitaka' berries, where the regression analysis showed a positive polynomial regression as the berries matured (Figure 5, Supplementary tables).
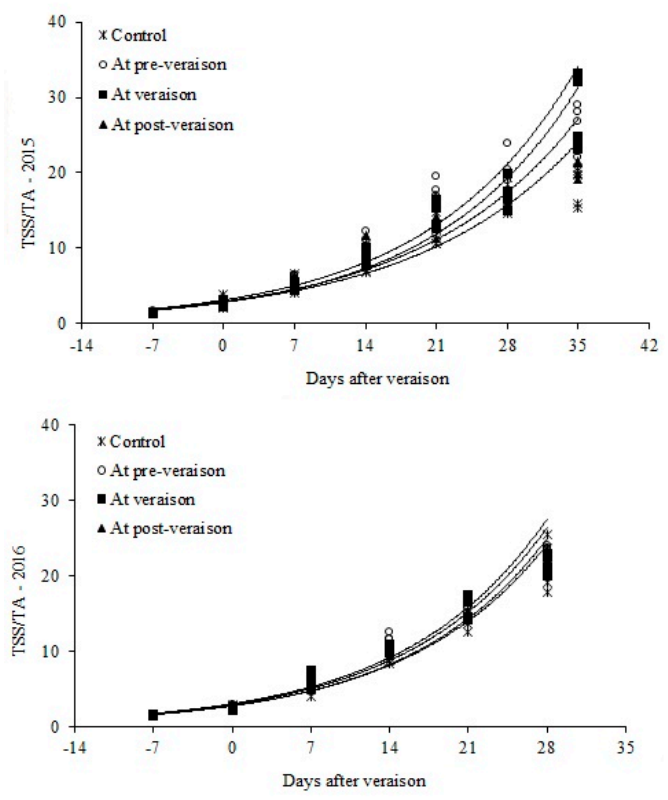

Figure 5. Evolution of maturation index (TSS/TA) of 'Benitaka' berries (Vitis vinifera L.) subjected to (S)-cis-abscisic acid (S-ABA $400 \mathrm{mg} \mathrm{L}^{-1}$ ) at different timings of veraison. A second application of S-ABA $400 \mathrm{mg} \mathrm{L}^{-1}$ was performed for all treatments 10 days after the first application, except for the control. Data were originated from polynomial regression. 


\section{Discussion}

It has been demonstrated that exogenous applications of S-ABA around the time of veraison increase the anthocyanin contents in the berry skin of several grape cultivars $[8,12,13,15-17]$. This can be attributed to the effects of $S$-ABA on the expression of genes related to anthocyanin biosynthesis and accumulation of metabolites in grape berries $[7,18,23]$. The use of ABA enhances the accumulation of the myb-related transcription factor VvMYBA1, regulator of UFGT (flavonoid 3-O-glucosyltransferase) gene expression [24-27], whereas the UFGT acts specifically for the production of anthocyanins [28,29].

Some table grape cultivars may respond well to a single application of S-ABA, such as 'Crimson Seedless' [13], whereas others, like 'Rubi' and 'Niagara Rosada', may need multiple applications to get such benefits $[30,31]$.

Rapid anthocyanin accumulation was observed among S-ABA-treated 'Cabernet Sauvignon' berries during early stages of ripening. Also, the anthocyanin synthesis differed among the two growing seasons of the trial, which can be attributed to the climatological differences among the two seasons [32]. Several environmental factors influence the anthocyanin accumulation in grape skin, including temperature, solar radiation, and the interaction between temperature and solar radiation [33]. Thus, the different pattern of anthocyanin accumulation during the two seasons may have occurred due to differences in the climatic conditions of the two seasons, especially the temperature and its diurnal temperature variation.

The early increase in anthocyanin contents may have occurred due to the fact that less mature berries respond well to $S$-ABA as compared to more ripe berries, in terms of anthocyanin accumulation and color development [16]. However, some cultivars respond well to late S-ABA application as well [12,13]. Meanwhile, in the current study, the timing of applying S-ABA had a longer range, where starting from PRV to POV all the treatments showed significant improvement in the anthocyanin contents of the berries, thus allowing a longer period of time for applying the plant growth regulator [16].

Regarding weekly rate of color development (Figure 2), treated berries tend to develop color faster. It can also be observed that berries that produce high color during early stages tend to produce lower daily color development during later stages of berry ripening. Decreases in berry color at later stages may be attributed to the degradation of anthocyanins by glycosidases and peroxidases [32]. During both seasons, the same pattern was observed, where the earlier S-ABA application (at PRV) showed a fast increase during early stages, but decreased over time, and similarly after each application the rate of color development increased in such manner. This behavior is related to the development of anthocyanins in the early stages of ripening. Since berries produced a rapid accumulation of anthocyanins at early stages of berry ripening due to early veraison applications (at PRV and at V) [16,31], this is the reason why the color development was also fast during early ripening stages.

The berries showed a predictable pattern of TSS improvement during both seasons. Similarly, no effect of S-ABA was observed over the TSS contents of 'Crimson Seedless' grapes, which ranged from 14 to 15 Brix [34]. The TSS of grapes is not usually influenced by the use of S-ABA [12,34], but rather on the environmental conditions and cultural practices [35]. As sugar is the dominant component $(90 \%)$ of TSS [35], its accumulation is mostly dependent on photosynthesizing leaves and woody storage parts [36] rather than use of S-ABA, and that is why a linear behavior was observed in the TSS development of 'Benitaka' berries. Application of S-ABA at different concentrations around veraison did not alter the chemical characteristics of 'Sovereign Coronation' grape berries [37]. The TA contents of 'Crimson Seedless' decreased during the course of berry ripening but with no influence from the S-ABA treatments [34]. Unlike TA, the maturation index increased in the same gradual manner that TA decreased, and with high maturation index at harvest of 'Monastrell' [38] as well as 'Chambourcin' grapes [39], where no effect of ABA application was found on the physicochemical properties of the berries. Several factors can influence the development of these variables and the results can vary according to the cultivar and the environmental conditions in the bunch ripening [40]. In berries of 'Flame Seedless', the application of exogenous S-ABA reduced the TA of berries [41]. 
This work was focused on investigating the anthocyanin accumulation, as well as the color development, during the course of berry ripening in response to exogenous S-ABA treatments at different timings of veraison. The study also focused on new aspects of anthocyanin and color development, such as the weekly rate of anthocyanin accumulation and weekly rate of CIRG, which have never been explored before. It was observed that S-ABA significantly improved the color development and anthocyanin accumulation in 'Benitaka' table grapes. Early application of the regulator produced faster anthocyanin accumulation during early weeks of veraison, which stabilized at the time of harvest.

During the 2016 off-season, this behavior slightly differed, but the role of S-ABA in the accumulation of anthocyanin and color development was the same in both cases. Daily rates of anthocyanin accumulation and CIRG followed a similar pattern. These analyses demonstrate that after the exogenous application of S-ABA the rate of daily anthocyanin peaked in response to the treatments, whereas the control treatment did not show any such response. A second application of $S$-ABA resulted in anthocyanin accumulation over time, as well as the color development of the 'Benitaka' grapes. This result supports the previous findings regarding 'Benitaka' and 'Rubi' table grapes grown in subtropical area $[9,15]$, since the levels of ABA decreased after one week of the exogenous S-ABA application. Thus, the second application of this plant growth regulator keeps the gene expression related to anthocyanin accumulation in higher levels, resulting in a better color coverage [29]. However, depending on the cultivar, a single application can be sufficient for color improvement, although when grown in warm areas, a second application is often necessary. The response of the berries towards S-ABA clearly showed that multiple applications of S-ABA are necessary to get such effects. The weekly rate of color and anthocyanin development provides a better idea regarding the amount of anthocyanin that accumulates in the berry skin on a daily basis and helps to establish a better understanding of the behavior of anthocyanin accumulation and its effect on the color development of berry skin. Similar to total anthocyanin accumulation and CIRG, the weekly rates of both variables also varied slightly between the two seasons, but this difference can be more attributed to the climate rather than the use of regulator itself, where a slight change in weather and climate can cause a significant difference in observations [35]. The regression analysis of physicochemical properties (i.e., TSS, TA, and maturation index) reveals that these variables depend on the natural phenology of the vine, as well as other factors including the environment, genotype, cultural practices, etc. However, he use of S-ABA had no observable impact on these variables, which followed a predictable pattern that is usually observed for this cultivar under similar environmental conditions.

\section{Conclusions}

For both the summer and off-season crops, treating 'Benitaka' grape berries pre- or at veraison with S-ABA significantly increased the anthocyanin accumulation as well as the color development of the berries. Other chemical properties of grapes (i.e., TSS, TA, and TSS/AT), were not affected by the use of $S$-ABA and followed a predictable pattern in relation to days of berry ripening.

Supplementary Materials: The following are available online at http:/ /www.mdpi.com/2073-4395/9/4/164/s1, Figure; Table S1. Regression equations for total soluble solids (TSS), titratable acity (TA) and TSS / AT evolution of 'Benitaka' berries (Vitis vinifera L.) subjected to (S)-cis-abscisic acid (S-ABA $400 \mathrm{mg} \mathrm{L}^{-1}$ ) at different timings of veraison. Summer season crop 2015, Table S2. Regression equations for total soluble solids (TSS), titratable acity (TA) and TSS / AT evolution of 'Benitaka' berries (Vitis vinifera L.) subjected to (S)-cis-abscisic acid (S-ABA $400 \mathrm{mg} \mathrm{L}^{-1}$ ) at different timings of veraison. Off-season crop 2016.

Author Contributions: S.R.R. conceived the research idea. M.S., S.A., R.C.C., J.P.S., R.K., and R.T.d.S. helped during collection of the data. M.S. also analyzed the data and wrote the paper.

Funding: The authors are grateful for the financial support provided by Brazilian National Council for Scientific and Technological Development (CNPq) and The World Academy of Sciences (TWAS) (Grant \#190194/2013-8).

Acknowledgments: The authors give their heartfelt thanks to the Londrina State University (UEL), Agronomy Department, Claudemir Zucarelli, Ines Cristina de Batista Fonseca, Fabio Yamashita, Antonio Martinez Peres, Josi Bonifacio, and Weda Westin for their help. 
Conflicts of Interest: The authors declare no conflict of interest.

\section{References}

1. Pezzuto, J.M. Grapes and human health: A perspective. J. Agr. Food Chem. 2018, 56, 6777-6784. [CrossRef] [PubMed]

2. Katalinić, V.; Možina, S.; Skroza, D.; Generalić, I.; Abramoviĉ, H.; Miloš, M.; Boban, M. Polyphenolic profile, antioxidant properties and antimicrobial activity of grape skin extracts of 14 Vitis vinifera varieties grown in Dalmatia (Croatia). Food Chem. 2010, 119, 715-723. [CrossRef]

3. Nixdorf, S.L.; Hermosín-Gutiérrez, I. Brazilian red wines made from the hybrid grape cultivar Isabel: Phenolic composition and antioxidant capacity. Anal. Chim. Acta. 2010, 659, 208-215. [CrossRef] [PubMed]

4. Lacampagne, S.; Gagné, S.; Gény, L. Involvement of Abscisic Acid in Controlling the Proanthocyanidin Biosynthesis Pathway in Grape Skin: New Elements Regarding the Regulation of Tannin Composition and Leucoanthocyanidin Reductase (LAR) and Anthocyanidin Reductase (ANR) Activities and Expres. J. Plant Growth Regul. 2010, 29, 81-90. [CrossRef]

5. Flamini, R.; Mattivi, F.; De Rosso, M.; Arapitsas, P.; Bavaresco, L. Advanced knowledge of three important classes of grape phenolics: anthocyanins, stilbenes and flavonols. Int. J. Mol. Sci. 2013, 14, 19651-19669. [CrossRef]

6. Owen, S.J.; Lafond, M.D.; Bowen, P.; Bogdanoff, C.; Usher, K.; Abrams, S.R. Profiles of abscisic acid and its catabolites in developing Merlot grape (Vitis vinifera) berries. Am. J. Enol. Viticult. 2009, 60, 277-284.

7. Koyama, K.; Sadamatsu, K.; Goto-Yamamoto, N. Abscisic acid stimulated ripening and gene expression in berry skins of the Cabernet Sauvignon grape. Funct. Integ. Genomics 2010, 10, 367-381. [CrossRef] [PubMed]

8. Peppi, M.C.; Fidelibus, M.W.; Dokoozlian, N. Abscisic acid application timing and concentration affect firmness, pigmentation and color of 'Flame Seedless' grapes. HortScience 2006, 41, 1440-1445. [CrossRef]

9. Roberto, S.R.; Assis, A.M.; Yamamoto, L.Y.; Miotto, L.C.V.; Sato, A.J.; Koyama, R.; Genta, W. Application timing and concentration of abscisic acid improve color of 'Benitaka' table grape. Sci. Hortic. 2012, 142, $44-48$. [CrossRef]

10. Kishino, A.A.; Marur, C.J.; Roberto, S.R. Caracteristicas da planta. In Viticultura Tropical: o sistema de produção de uvas de mesa do Paraná; Kishino, A.Y., Carvalho, S.L.C., Roberto, S.R., Eds.; IAPAR Publishing: Londrina, Brazil, 2018; pp. 155-249.

11. Leão, P.C.S.; Soares, J.M.; Rodrigues, B.L. Principais cultivares. In A Vitivinicultura no Semiárido Brasileiro; Soares, J.M., Leão, P.C.S., Eds.; Embrapa Informação Tecnológica: Brasília, Brazil, 2009; pp. 151-214.

12. Peppi, M.C.; Fidelibus, M.W.; Dokoozlian, N. Application timing and concentration of abscisic acid affect the quality of 'Redglobe' grapes. J. Hortic. Sci. Biotechnol. 2007, 82, 304-310. [CrossRef]

13. Peppi, M.C.; Fidelibus, M.W.; Dokoozlian, N. Timing and concentration of abscisic acid applications affect the quality of 'Crimson Seedless' grapes. Int.l J. Fruit Sci. 2007, 7, 71-83. [CrossRef]

14. Deis, L.; Canagnaro, B.; Rubens, B.; Wuilloud, R.; Silva, M.F. Water deficit and exogenous ABA significantly affect grape and wine phenolic composition under in field and in vitro conditions. Plant Growth Reg. 2011, 65, 11-21. [CrossRef]

15. Roberto, S.R.; De Assis, A.M.; Yamamoto, L.Y.; Miotto, L.C.V.; Koyama, R.; Sato, A.J.; Borges, R.S. Ethephon use and application timing of abscisic acid for improving color of 'Rubi' table grape. Pesqui. Agropecu. Bras. 2013, 48, 797-800. [CrossRef]

16. Yamamoto, L.Y.; Koyama, R.; De Assis, A.M.; Borges, W.F.S.; De Oliveira, I.R.; Roberto, S.R. Color of berry and juice of 'Isabel' grape treated with abscisic acid in different ripening stages. Pesqui. Agropecu. Bras. 2015, 50, 1160-1167. [CrossRef]

17. Koyama, R.; Assis, A.M.; Yamamoto, L.Y.; Borges, W.F.; Borges, R.S.; Prudêncio, S.H.; Roberto, S.R. Exogenous abscisic acid increases the anthocyanin concentration of berry and juice from 'Isabel' grapes (Vitis labrusca L.). HortScience 2014, 49, 460-464. [CrossRef]

18. Giribaldi, M.; Hartung, W.; Schubert, A.S. The effects of abscisic acid on grape berry ripening are affected by the timing of treatment. J. Int. Sci. Vigne. Vin. 2010, 44, 9-15.

19. Caviglione, J.H.; Kiihl, L.R.B.; Caramori, P.H.; Oliveira, D. Cartas climáticas do Paraná; IAPAR Publishing: Londrina, Brazil, 2000. 
20. Carreño, J.; Martínez, A.; Almela, L.; Fernández-López, J.Á. Proposal of an index for the objective evaluation of the color of red table grapes. Food Res. Int. 1995, 28, 373-377. [CrossRef]

21. Instituto Adolfo Lutz. Normas analíticas do Instituto Adolfo Lutz: métodos químicos e físicos para análise dos alimentos, 3rd ed.; Instituto Adolfo Lutz: São Paulo, Brazil, 2008.

22. Tukey, J.W. Comparing individual means in the analysis of variance. Biometrics 1949, 5, 99-114. [CrossRef]

23. Villalobos-González, L.; Peña-Neira, A.; Ibáñez, F.; Pastenes, C. Long term effects of abscisic acid (ABA) on the grape berry phenylpropanoid pathway: Gene expression and metabolite content. Plant Physiol. Bioch. 2016, 105, 213-223. [CrossRef]

24. Boss, P.K.; Davies, C.; Robinson, S.P. Expression of anthocyanin biosynthesis pathway genes in red and white grapes. Plant Mol. Biol. 1996, 32, 565-569. [CrossRef]

25. Kobayashi, S.; Ishimaru, M.; Hiraoka, C.; Honda, C. MYB-related genes of the Kyoho grape (Vitis labruscana) regulate anthocyanin biosynthesis. Plant Sci. 2002, 215, 924-933.

26. Jeong, S.T.; Goto-Yamamoto, N.; Kobayashi, S.; Esaka, M. Effects of plant hormones and shading on the accumulation of anthocyanins and the expression of anthocyanin biosynthetic genes in grape berry skin. Plant Sci. 2004, 167, 247-252. [CrossRef]

27. Azuma, A.; Kobayashi, S.; Yakushiji, H.; Yamada, M.; Mitani, N.; Sato, A. VvMYBA1 genotype determines grape skin color. Vitis 2007, 46, 154-155.

28. Roubelakis-Angelakis, K.A. Grapevine Molecular Physiology and Biotechnology, 2nd ed.; Springer: Dordrecht, The Netherlands, 2009.

29. Koyama, R.; Roberto, S.R.; de Souza, R.T.; Borges, W.F.S.; Anderson, M.; Waterhouse, A.L.; Cantu, D.; Fidelibus, M.W.; Blanco-Ulate, B. Exogenous Abscisic Acid Promotes Anthocyanin Biosynthesis and Increased Expression of Flavonoid Synthesis Genes in Vitis vinifera $\times$ Vitis labrusca Table Grapes in a Subtropical Region. Front. Plant Sci. 2018, 9, 323. [CrossRef] [PubMed]

30. Domingues-Neto, F.J.; Junior, S.P.; Borges, C.V.; Cunha, S.R.; Callili, D.; Lima, G.P.P.; Roberto, S.R.; Leonel, S.; Tecchio, M.T. The exogenous application of abscisic acid induces accumulation of anthocyanins and phenolic compounds of the 'Rubi' grape. Am. J. Plant Sci. 2017, 8, 2422-2432. [CrossRef]

31. Tecchio, M.A.; Neto, F.J.D.; Junior, A.P.; Da Silva, M.J.R.; Roberto, S.R.; Smarsi, R.C. Improvement of color and increase in anthocyanin content of 'Niagara Rosada' grapes with application of abscisic acid. Afr. J. Biotechnol. 2017, 16, 1400-1403.

32. Gagné, K.; Esteve, K.; Deytieux, C.; Saucier, C.; Geny, L. Influence of abscisic acid in triggering "véraison » in grape berry skins of Vitis vinifera L. cv. Cabernet Sauvignon. J. Int. Sci. Vigne Vin 2006, 38, 7-14. [CrossRef]

33. Tarara, J.; Lee, J.; Spayd, S.; Scagel, S. Berry temperature and solar radiation alter acylation, proportion, and concentration of anthocyanin in Merlot grapes. Am. J. Enol. Vitic. 2008, 59, 235-247.

34. Ferrara, G.; Mazzeo, A.; Matarrese, M.A.S.; Pacucci, C.; Punzi, R.; Faccia, M.; Trani, A.; Gambacorta, G. Application of abscisic acid (S-ABA) and sucrose to improve color, anthocyanin content and antioxidant activity of cv. crimson seedless grape berries. Aust. J. Grape Wine Res. 2015, 21, 18-29. [CrossRef]

35. Keller, M. The Science of Grapevines: Anatomy and Physiology, 2nd ed.; Elsevier Academic Press: London, UK, 2015.

36. Rebucci, B.; Poni, S.; Intrieri, C.; Magnanini, E.; Lakso, N.A. Effect of manipulated grape berry transpiration and post-veraison sugar accumulation. Aust. J. Grape Wine Res. 1997, 3, 57-65. [CrossRef]

37. Reynolds, A.; Robbins, N.; Lee, H.S.; Kotsaki, E. Impacts and Interactions of Abscisic Acid and Gibberellic Acid on Sovereign Coronation and Skookum Seedless Table Grapes. Am. J. Enol. Vitic. 2016, 67, 327-338. [CrossRef]

38. Ruiz-García, Y.; Gil-Muñoz, R.; López-Roca, J.M.; Martínez-Cutillas, A.; Romero-Cascales, I.; Gómez-Plaza, E. Increasing the Phenolic Compound Content of Grapes by Preharvest Application of Abcisic Acid and a Combination of Methyl Jasmonate and Benzothiadiazole. J. Agr. Food Chem. 2013, 61, 3978-3983.

39. Zhang, Y.; Dami, I. Improving freezing tolerance of 'Chambourcin' grapevines with exogenous abscisic acid. HortScience 2012, 47, 1750-1757. [CrossRef] 
40. Jackson, R.S. Wine Science: Principles and Applications, 3rd ed.; Elsevier: Amsterdam, The Netherlands, 2008.

41. Peppi, M.C.; Walker, M.A.; Fidelibus, M.W. Application of abscisic acid rapidly upregulated UFGT gene expression and improved color of grape berries. Vitis 2008, 47, 11-14.

(c)

(C) 2019 by the authors. Licensee MDPI, Basel, Switzerland. This article is an open access article distributed under the terms and conditions of the Creative Commons Attribution (CC BY) license (http://creativecommons.org/licenses/by/4.0/). 